\title{
Method of the Shortcut Estimation of Rails Reliability by the Fatigue Strength Criterion
}

\author{
L. A. Sosnovskii, ${ }^{a}$ N. A. Makhutov, ${ }^{\text {b }}$ V. I. Matviatsov, ${ }^{c}$ and A. A. Kebikove \\ ${ }^{a}$ S\&P Group Tribofatigue Ltd., Gomel, Belarus \\ b Blagonravov Institute of Machine Science, Russian Academy of Sciences, Moscow, \\ Russia \\ ${ }^{c}$ Belarusian State University of Transport, Gomel, Belarus
}

\begin{abstract}
The diagram of damage of structural steels under bending and contact loading has been constructed. The criterion of the critical state of steels is proposed, which corresponds to the formation of incipient surface cracks in the rolling friction zone. The methods of shortcut estimation of the damaged state of railway rails, which provide prediction of their reliability and life under service conditions, are proposed. A set of experimental studies is made with objectives to justify the proposed diagram, criterion and methods.
\end{abstract}

Keywords: structural steel, fatigue resistance, strength, hardness, critical state, damage state, estimation methods, railway rail.

Calculation and experimental methods have found wide use in estimating the mechanical fatigue resistance of materials and structural components. The general convention is that the endurance limit $\sigma_{-1}$ is calculated in terms of some mechanical characteristics that are determined by simple experimental tests. Numerous theoretical and experimental works [1-3] deal with study of the interrelation between various mechanical characteristics of steels.

Only few works [e.g., 4, 5] discuss the relationships between the contact fatigue limit (for pure rolling friction) and the mechanical characteristics of steels. However, such relationships have not gained further generalization, which would make it possible to predict both the damaged and the critical states of steels in terms of the fatigue resistance criterion.

The service defects of rails were analyzed in many works $[6,7$, etc.]. However, up to now the substantiated methods of estimation of the mechanical state and the damage of rails in operation are practically not available.

Therefore, our aim was to develop the criterion and the methods of estimation of the damaged state of structural steels, including railway rails under operating conditions.

A generalized analysis of a wide range of experimental data [1-7], which is supplemented with the results on steel tests for railway rails and wheels [8] has been performed. As a result, the state diagram of damage of structural (carbon and alloyed) steels has been constructed, which characterized the relations between the endurance limits under contact loading $\left(p_{f}\right)$ and bending $\left(\sigma_{-1}\right)$ conditions, the tensile strength limit $\left(\sigma_{b}\right)$, Brinell hardness $(H B)$ and Vickers hardness $(H V)$ (Fig. 1). The investigated steels varied by chemical composition and structural states obtained by the respective heat treatment. The above- 


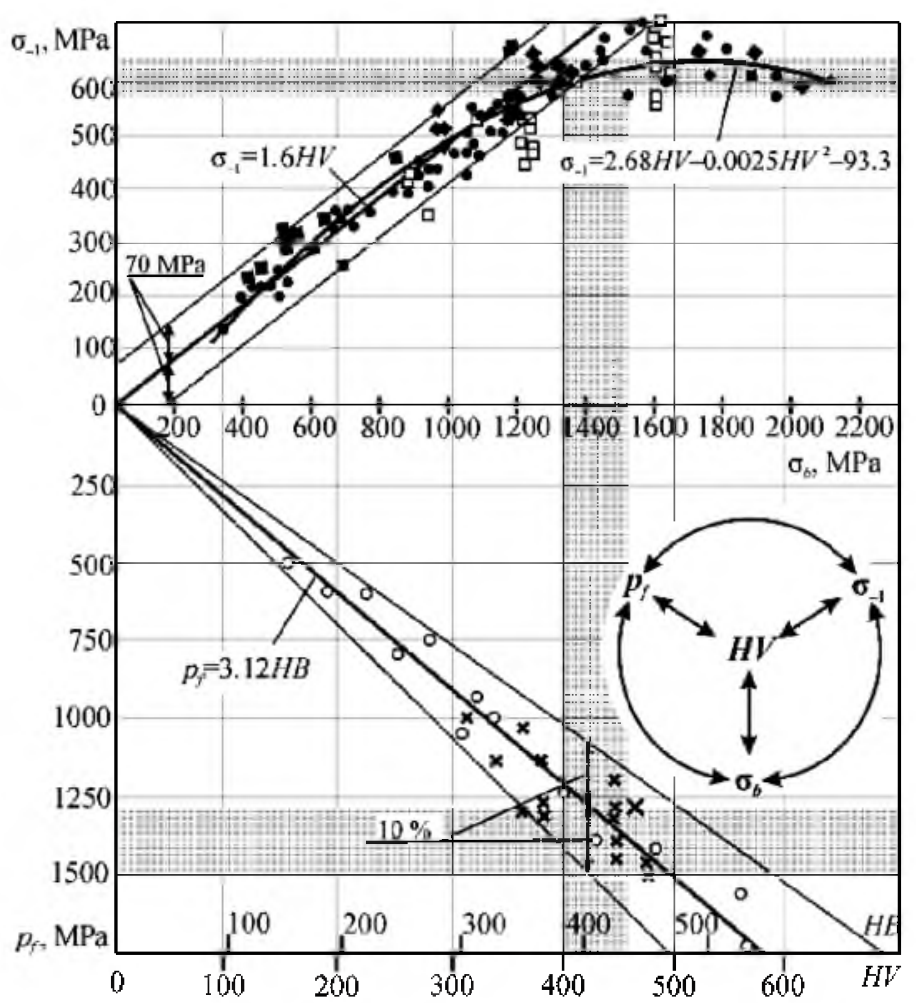

Fig. 1. The diagram of damage of structural steels.

mentioned relationships for the ring scheme in Fig. 1 have been experimentally determined and are described by the following relations

$$
\begin{gathered}
p_{f}=3.12 \mathrm{HB}, \quad \sigma_{-1}=0.5 \sigma_{b}, \quad \sigma_{b}=3.5 \mathrm{HB}, \\
\sigma_{-1}=1.6 \mathrm{HV} \quad\left(\sigma_{-1}<500 \mathrm{MPa}\right), \\
\sigma_{-1}=2.68 \mathrm{HV}-0.0025 \mathrm{HV}^{2}-93.3 \quad\left(\sigma_{-1}>400 \mathrm{MPa}\right) .
\end{gathered}
$$

The basic regularity integrally described by the diagram is such: the increase in the fatigue resistance of structural steel attained by different hardening methods occurs in accord with the growth of its hardness (strength). The diagram has one specific feature: the dependence of $\sigma_{-1}\left(\sigma_{b}\right)$ is extreme: at $\sigma_{b} \sim 1400 \mathrm{MPa}$ the limit of bending hardness $\sigma_{-1}$ manifest the initial growth with increasing steel strength, but then has a tendency to decrease. This allows us to propose the following set of interrelated characteristics (Fig. 1, shaded) controlling the transition of structural steels to the critical state:

$$
\left\{\begin{array}{l}
550 \leq \sigma_{-1}^{(c)} \leq 650 \mathrm{MPa} \\
1200 \leq p_{f}^{(c)} \leq 1300 \mathrm{MPa} \\
380 \leq H B^{(c)} \leq 420
\end{array}\right.
$$




$$
\left\{\begin{array}{l}
400 \leq H V^{(c)} \leq 440, \\
1300 \leq \sigma_{b}^{(c)} \leq 1500 \mathrm{MPa} .
\end{array}\right.
$$

As applied to the behavior of steel determined under operating conditions, the diagram (Fig. 1) may have the following interpretation. If the hardness (strength limit) grows in operation, this testifies that the fatigue resistance increases at a time. Such increase represents the process of steel hardening under operating conditions and proceeds until transition into the critical region occurs for the dependence $\sigma_{-1}(H V)$ (shaded in Fig. 1). This is the region where the surface damage starts. Thus, Fig. 1 can be considered as the state diagram of steel damage in terms of bending and contact fatigue criteria and (2) as the criterion for the critical state of structural steels.

Figure 1 yields another important practical conclusion: the increase in steel hardness by more than $\approx 400 \mathrm{HV}$ is ineffective for systems that are operating under cyclic conditions, when bending and contact stresses are excited simultaneously and in the only (dangerous) region, i.e., in contact mechanical fatigue.

Since the mechanical state of steel can be estimated by the total set of the considered mechanical characteristics presented in Eq.(2) and by any of them, for practical purposes it is recommended to use the methods of estimation of the mechanical state of steel that are based on measuring of Vickers hardness. The hardness was investigated for the railway rails of the Minsk city subway. The objects of investigation were railroad rail pieces: 1) new ones that have not been in use; 2) rails after operation time correponding to $300 \mathrm{mln}$ ton gross, i.e., normative tonnage that characterizes the total operating time of rails. Afterthe latter is achieved, the rails should be replaced irrespective of the fact whether their serviceability is exhausted or not; 3) after operating time of $210 \mathrm{mln}$ ton gross. The scheme of measuring the Vickers hardness $H V$ at the rolling surface of a rail is shown in Fig. 2. Over the surface section $40 \times 90 \mathrm{~mm}$ in size 2500 points were marked, at each of which the Vickers hardness was determined.

For the used rails it is established that the surface layer of metal in a wheel rolling over a rail is deformed unevenly - the specific regions (Fig. 2) determined by a sharp change in the hardness distribution fields are revealed. These zones are nonuniform both in width and length of the rail head.

Figure 3 shows the obtained data analyzed using the state diagram of damage of structural steels (Fig. 1). The solid vertical straight line stands for the initial state (before operation $\overline{H V}=261$ ). The dotted lines correspond to characteristic deformation zones $I, I I$, and $I I I$ after operating time of $300 \mathrm{mln}$ ton gross. It is seen that in zone $I I I \overrightarrow{H V}=320)$ the critical state is far short of being attained, whereas that of the metal surface layer in zone $I I(\overline{H V}=410)$ is consistent with the start of the critical state. But in zone $I$ criterion (1) for the critical state is exceeded $\left(\overline{H V}=480>H V^{(c)}\right)$. However it should be noted that this zone occupies a small section of the rolling surface (up to $8 \%$ ); hence, it can be assumed that the used rails did not exhaust their serviceability.

Such a conclusion has been supported by conducting comprehensive experimental studies of the microstructure of rail steel before and after use, by 

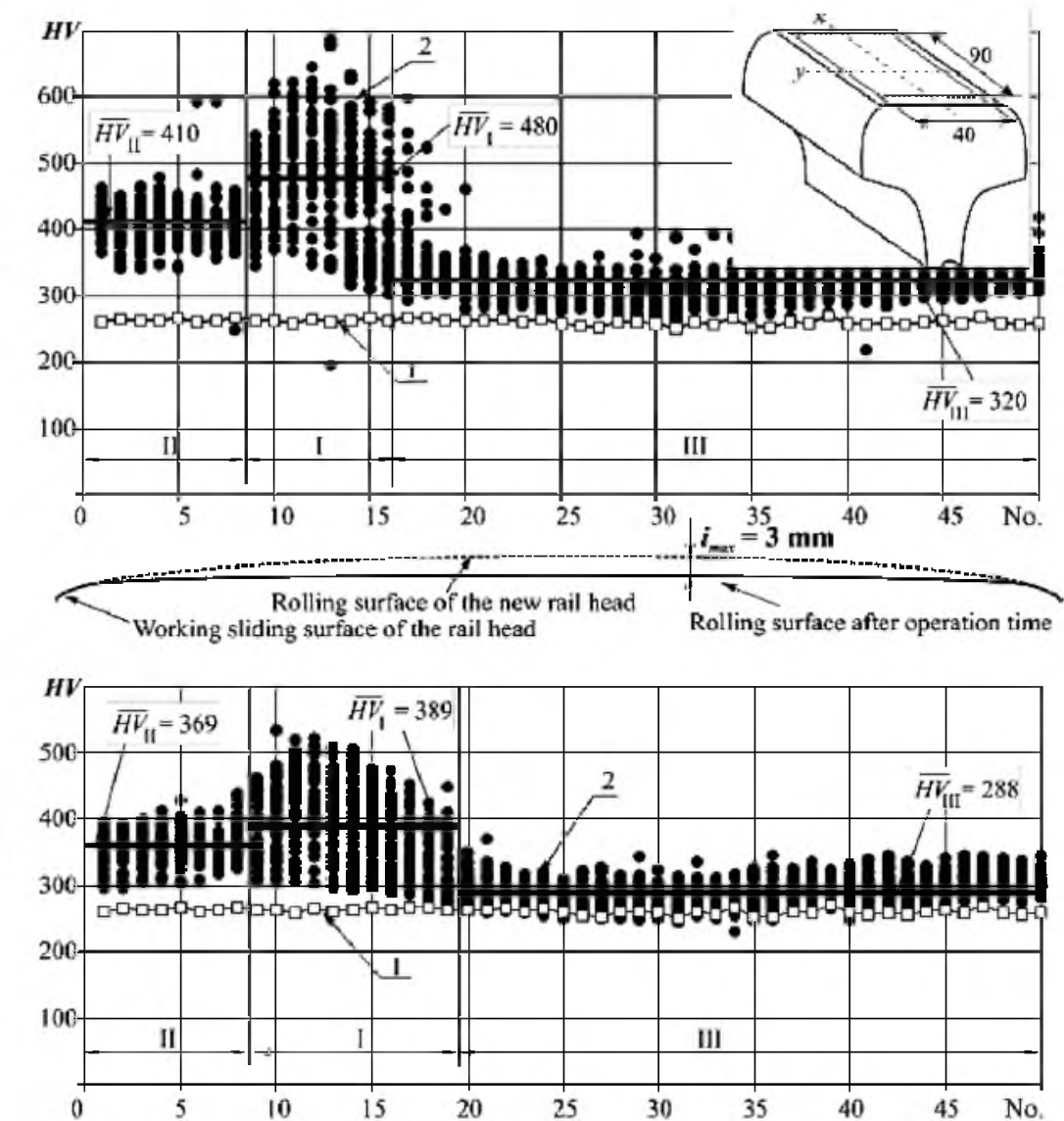

Fig. 2. Typical distribution of hardness $H V$ over the rolling surface of the rail head after operating time of 300 (a) and 210 (b) mln ton gross [(1) mean hardness before use; (2) hardness distribution after use].

analyzing the statistics of rail failures, as well as by studying the anisotropy and the character of distribution of material properties at the rolling surface of rails.

The metallographic analysis of the samples of the rails before and after use allows estimation of the damaged state of rail steel at the rolling surface in terms of the abundant defects and deformation level. The microstructure of rail steel for a new rail is shown in Fig. 3 in the left lower corner; for the largest deformation region - zone $I$ for a rail after having been used - in Fig. 3 in the upper right corner. In the both cases the structure of the core of the samples is characterized by the presence of sorbite-like perlite, as well as of separate zones of fine-plate perlite. An embrilltled layer is seen in the surface layer of zone $I$ of the rail sample with operating time of $300 \mathrm{mln}$ ton gross. The density of dislocations in this layer is approximately $8-10$ times higher than that in the bulk material. The application of the methods of metallographic analysis in this zone has permitted revealing inclined cracks (Fig. 4a-c) formed under operating conditions. Moreover, some internal cracks are observed, which are not exposed along the surface and are oriented mainly parallel to the surface (Fig. 4d). The depth of occurrence of cracks varies from 17 to $210 \mu \mathrm{m}$, the length - from 25 to $2000 \mu \mathrm{m}$. 


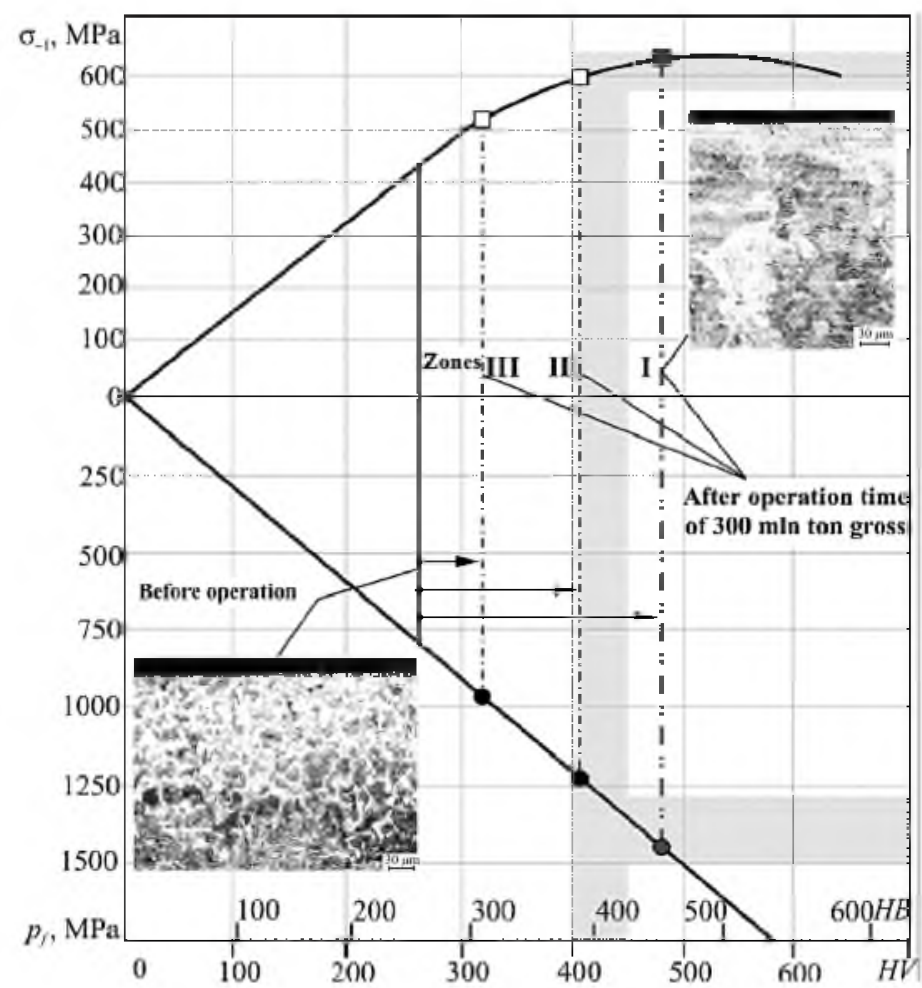

Fig. 3. Diagram of the mechanical state of rail steel after operating time of $300 \mathrm{mln}$ ton gross.

In addition, the similar studies of the rails with operating time of $210 \mathrm{mln}$ ton gross are carried out. In this case, the metallographic analysis has revealed no operation damages similar to those shown in Fig. 4.

The analysis of the data plotted in Figs. 1-4 leads to the general conclusion that in operation there occurs spontaneous strengthening of material at the rolling surface of a rail. According to our data, the strength level estimated by the hardness growth increases with operating time in all zones and especially in zone $I$ (up to 1.5-2.0 times) In the latter case, approximately twofold increase in the strength level is followed by transition to the strength reduction due to development of microcracks. It can be assumed that the critical state according to (1) also corresponds to the above transition.

Thus, it has been confirmed by the metallographic analysis that the proposed diagram of the mechanical state of steels permits one to correctly estimate the damaged state of rail steels under operating conditions as well as to predict the onset of the critical state.

The statistics and the character of operation failures characterize the reliability and serviceability of railway rails. The accumulated specific failures of rails (pieces $/ \mathrm{km}$ ) - the failures pertained to the length of the railway section were used as the parameter for the serviceability of rails under operating conditions. Figure 5 presents the statistical results on rail failures in the line of the Minsk city subway, whose length is $18.99 \mathrm{~km}$, for 21 years of operation after operating time of $315 \mathrm{mln}$ ton gross. 

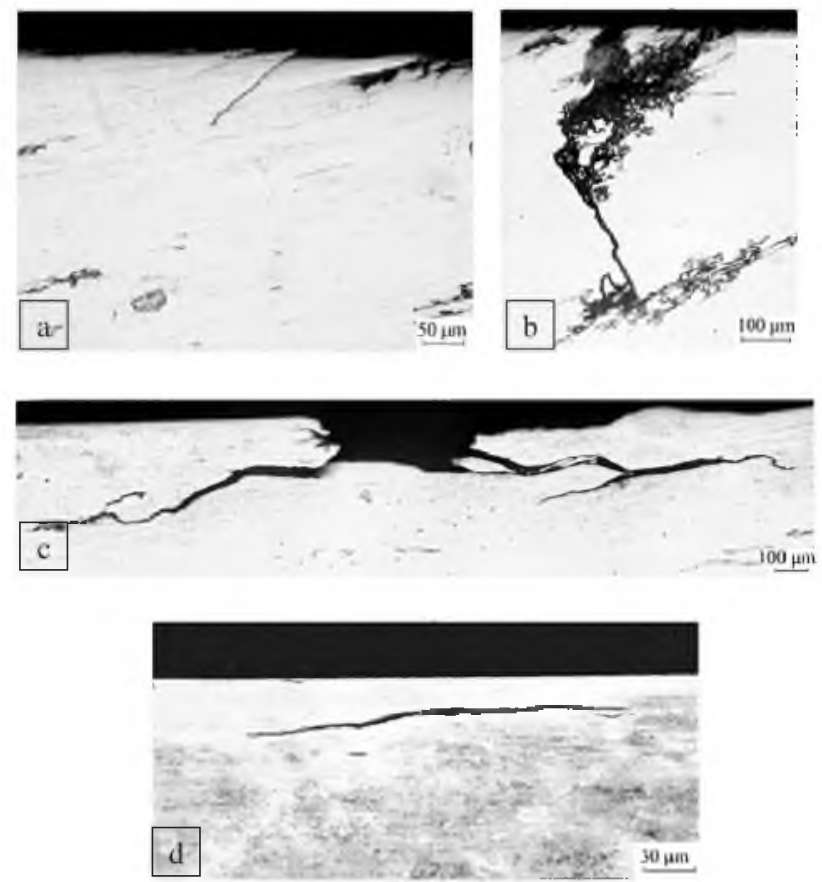

Fig. 4. Incipient fatigue cracks found in zone $I$ (operating time of $300 \mathrm{mln}$ ton gross).

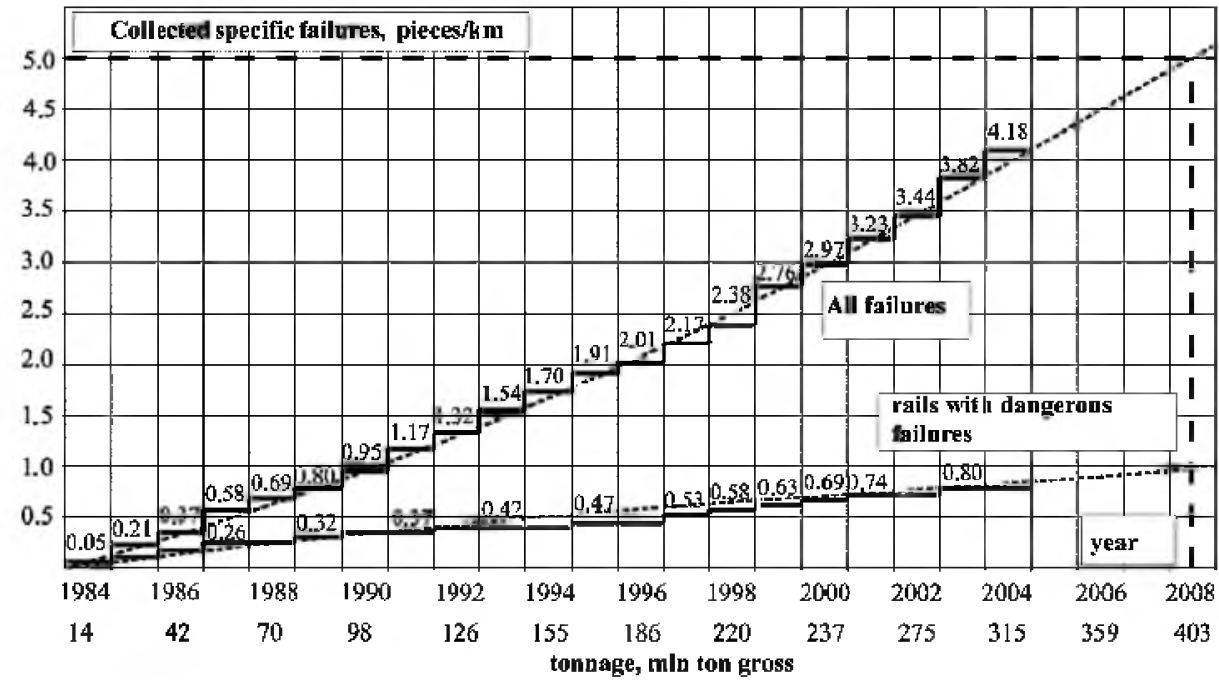

Fig. 5. Collected specific failures of rails vs. operating time.

As follows from the above data, for the rate of rail failures, which is over the recent years, on the average, 0.28 pieces $/ \mathrm{km}$, and for the mean density of freight traffic, which is $22 \mathrm{mln}$ ton gross in the line per year, the attained rate of failures of 5 pieces $/ \mathrm{km}$ the rail tonnage will be $\sim 410 \mathrm{mln}$ ton gross, i.e., the rails can opeerate approximately for 4 years.

The performed studies of the structure and the failure rate of rails form a sound base for the serviceability prediction of rails in terms of criterion (2). 
To examine the material properties at the rolling surface of a rail, the shortcut nondestructive control method has been used to study the anisotropy factor. The ratio $d x / d y$ of the diagonals of pyramid imprints in the longitudinal and transverse directions is proposed to be used as the anisotropy factor. It is found that the value of the anisotropy factor $K_{A}=d x / d y$ for material in the initial state varies from 0.944 to 1.050 , on the average, accounting for 0.997 . Thus, it can be stated that before operation the rail material is practically isotropic.

The value of the anisotropy coefficient $K_{A}$ for each of the characteristic deformation zones is different. Thus, for zone $I$ it is, on the average, 0.965 ; for zone $I I-0.978$; for zone $I I I-0.982$. In addition, for all characteristic deformation zones it appears that usually $d x<d y$. All this points to the development (in the process of operation) of the deformation anisotropy of the material properties; this regularity is known and is established by the non-destructive control methods in the tensile or shock viscosity tests of the samples cut in the longitudinal and transverse directions.

The anisotropy of the material properties at the rolling surface of the rail head is indicative of the fact that as (2) forecasts, in zone $I$ with the hardness values higher than the critical ones the initial layer-by-layer damages of material are expected to form. Such defects were seen in the analysis of the microdeformations of the rails, whose operating time was $300 \mathrm{mln}$ ton gross (Fig. 4). Moreover, this supports the proposed criterion and the methods of estimating the damaged state of railway rails.

The general conclusion is that the performed comprehensive experimental investigations have substantiated the proposed diagram and the criterion of the critical state of steels, as well as the methods of estimating the damaged state of rails under operating conditions.

1. R. B. Heywood, Designing Against Fatigue, Chapman \& Hall Ltd., London (1962).

2. V. T. Troshchenko and L. A. Sosnovskii, Fatigue Resistance of Metals and Alloys [in Russian], Naukova Dumka, Kiev (1987).

3. L. A. Sosnovskii, Mechanics of Fatigue Failure [in Russian], SPG Tribofatigue Press, Gomel (1994).

4. A. F. Zolotarskii, Thermally Shortened Rails [in Russian], Transport, Moscow (1976).

5. A. A. Susin, Chemical-Thermal Impregnation of High-Stressed Parts [in Russian], Belorusskaya Navuka, Minsk (1999).

6. W. Harris, Guideliness to Best Practice for Heavy Haul Operations: Wheel and Rail Interface Issuses, IHHA, Virginia Beach, USA (2001).

7. J. N. Beynon "Surface metallurgy and rolling contact fatigue and wear of rail," in: Proc. of the 7th Int. Conf. on Contact Mechanics and Wear of Rail/Wheel Systems (Brisbane, Australia, 2006), Brisbane (2006).

8. N. A. Makhutov, L. A. Sosnovskii, and A. A. Kebikov, "Method of estimating the mechanical state of the material of the rails after long service," Zavod. Lab., Diagn. Mater., 73, No. 4, 49-54 (2007).

Received 11.08. 2008 